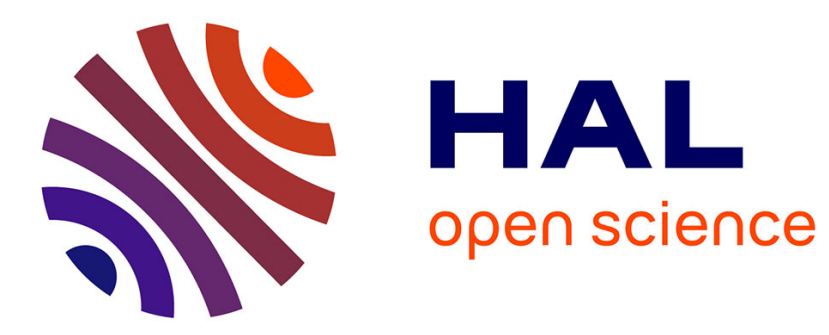

\title{
Synthesis and Characterization of Adamantane-Containing Heteropeptides with a Chirality Switch
}

Adriano Aloisi, Niels Christensen, Kasper Sørensen, Chloe Guilbaud, Knud Jensen, Alberto Bianco

\section{To cite this version:}

Adriano Aloisi, Niels Christensen, Kasper Sørensen, Chloe Guilbaud, Knud Jensen, et al.. Synthesis and Characterization of Adamantane-Containing Heteropeptides with a Chirality Switch. European Journal of Organic Chemistry, 2020, 2020 (7), pp.815-820. 10.1002/ejoc.201901666 . hal-02916774

\section{HAL Id: hal-02916774 \\ https://hal.science/hal-02916774}

Submitted on 17 Aug 2020

HAL is a multi-disciplinary open access archive for the deposit and dissemination of scientific research documents, whether they are published or not. The documents may come from teaching and research institutions in France or abroad, or from public or private research centers.
L'archive ouverte pluridisciplinaire HAL, est destinée au dépôt et à la diffusion de documents scientifiques de niveau recherche, publiés ou non, émanant des établissements d'enseignement et de recherche français ou étrangers, des laboratoires publics ou privés. 


\section{Synthesis and characterization of adamantane-containing heteropeptides with a chirality switch}

Adriano Aloisi,, Niels Johan Christensen," Kasper K. Sørensen, Chloé Guilbaud-Chéreau, Knud J. Jensen, *Alberto Bianco*

Dr. A. Aloisi, C. Guilbaud-Chéreau, Dr. A. Bianco

University of Strasbourg, CNRS, Immunology, Immunopathology and Therapeutic

Chemistry, UPR 3572, 67000 Strasbourg, France.

E-mail: a.bianco@ibmc-cnrs.unistra.fr

http://www-ibmc.u-strasbg.fr/spip-ict/rubrique8.html?lang=fr

Dr. Niels Johan Christensen, Dr. Kasper K. Sørensen, Prof. K.J. Jensen

Department of Chemistry, University of Copenhagen, Thorvaldsensvej 40, DK-1871

Frederiksberg, Denmark.

E-mail: kjj@chem.ku.dk

https://kjj-lab.org

${ }^{\#}$ These authors contributed equally to this work

Keywords: Diamond; foldamers; solid-phase peptide synthesis; circular dichroism; molecular dynamics simulations. 


\begin{abstract}
Oligomers assembled from designed building blocks to fold in novel ways have emerged as tools and allow the creation of new structures and molecular properties. Here we describe the use of a highly constrained adamantane moiety with one amino group and three carboxylic acids as a monomer. It can be viewed as a constrained, $\alpha, \alpha$-dialkylated $\gamma$-amino tri-acid with side-chains that mimic glutamic acid. We alternated this amino acid with glycine to synthesize a heteropeptide adamantane-based oligomer. We included an N-terminal L- or D-tyrosine to investigate possible chirality induction. The oligomer was assembled by solid-phase peptide synthesis using Fmoc- and Boc-protection strategies. This novel oligomer was characterized by circular dichroism spectroscopy, which revealed a clear effect from the chirality of the Nterminal tyrosine. Molecular dynamics simulation indicated that the adamantane oligomers populated compact conformations, with a subset forming cyclic geometries by hydrogen bonding. Through these interactions the chirality of Tyr induced an overall chirality in the cyclic conformations. This is in agreement with the spectroscopic data. This points to the use of adamantane building blocks in novel chirality switches.
\end{abstract}




\section{Introduction}

Foldamers are natural or non-natural polymers that have a strong tendency to fold into one, ${ }^{[1]}$ or more, ${ }^{[2]}$ well-defined conformations stabilized by non-covalent interactions. ${ }^{[3-5]}$ Peptidomimetic-based foldamers are designed to mimic natural peptide conformations, generating a rich source of diversity. ${ }^{[6]}$ They are readily synthesized, for example by solid-phase peptide synthesis (SPPS) and can be rationally designed by modification of the monomeric building blocks leading to new folding properties. This has been utilized in the development of new peptide foldamer families, such as $\beta$-peptides, $\gamma$-peptides, azapeptides and aminoxy acid containing oligomers. ${ }^{[7]}$

The combination of different types of monomers in a single sequence, a heteropeptide, yields a practically limitless number of new designs. Within a foldamer family, fine-tuning of the monomeric building block can lead to substantially different types of conformations. For example, $\alpha ß$-peptides using a $\beta$-residue with a five membered-ring adopt helical secondary structures (11-helix or 14/15 helix) in solution. ${ }^{[8]}$ In another study focusing on hexameric Bpeptides, the bulky and bicyclic diexo-3-aminobicyclo[2.2.1]hept-5-ene2-carboxylic acid monomer led to a cyclic conformation, while the less bulky cis-2-aminocyclohex-3-ene carboxylic acid residue promoted helix formation. ${ }^{[9]}$ The demonstration of binding of designed $\beta$ - and $\gamma$-peptides to natural $\alpha$-peptide receptors suggests potential therapeutic applications of such foldamers. ${ }^{[7]}$ Indeed, the tunable molecular conformations of the foldamers provide them with intrinsic properties, which can play a role in recognition and inhibition of several targets such as bacterial cell membranes, ${ }^{[10]}$ proteins and RNA, ${ }^{[11,12]}$ and lectins. ${ }^{[13]}$

Some important precedents to the current work include the systematic computational exploration of periodic secondary structures of $\beta / \gamma$ - and $\alpha / \gamma$-octamers with unsubstituted backbones. ${ }^{[14]}$ The stereospecific synthesis of $\gamma$-amino acids with a cyclohexyl constraint on the $\mathrm{C}_{\beta}-\mathrm{C}_{\gamma}$ bond and a variable $\mathrm{C}_{\alpha}$ side chain, leading to helical foldamers of which several variants were later crystallized to understand helix formation, ${ }^{[15]}$ is also relevant. ${ }^{[16]}$ Further work on 
these systems demonstrated the necessity of $\gamma$-backbone cyclization to promote 12-helix formation in water, but not in methanol. ${ }^{[17]}$

In this study, we combined the remarkable structure and chemical properties of adamantane (Ada) with regular $\alpha$-amino acids to design new $\alpha, \gamma$-heteropeptides as biomimetic scaffolds. Ada can be viewed as a constrained $\alpha, \alpha$-dialkylated $\gamma$-amino acid with three side-chains that mimic glutamic acid. Substitution at the four bridgehead positions of Ada enable the design of polyfunctional building blocks for foldamer synthesis. With the appropriate protection steps, it is possible to obtain an adamantane-based amino acid that can be used for solid-phase synthesis of novel peptide foldamers incorporating the adamantane moiety into their backbones. Our aim was to exploit the rigid and well-defined structure of adamantane to induce specific conformations. To this end, we synthesized a C-3 symmetrical $\gamma$-amino acid based on the Ada core with one amino and three carboxylic acid functions. This amino acid was used to build short peptides with repeated achiral Gly-Ada units. A single N-terminal L- or D-tyrosine was used as chirality inducer. A series of these Ada-containing heteropeptides was prepared and fully characterized. We found that they are able to form an ensemble of chiral conformations as proved by circular dichoism and molecular dynamics simulations.

\section{Results and discussion}

Adamantane is a molecule that has been exploited in the biological field as core for the development of new drugs or to build dendritic structures. ${ }^{[18,19]}$ Recently, we have optimized the synthesis of C-3 symmetrical $\gamma$-amino acid Ada 1 (Scheme 1) to build a new class of dendrimers. ${ }^{[20]}$ We exploited these molecules to enhance the anti-inflammatory capacity of ibuprofen or as multivalent system to present a peptide to modulate autoimmune dysfunctions. ${ }^{[21,22]}$ We hypothesized that a rigid core would allow to maintain the peripheral functional groups well-oriented in space, imparting a certain rigidity to the dendrimer and likely play a key role in the multivalent properties. As Ada is a highly constrained molecule, we 
decided to exploit this property further by inserting Ada into a peptide sequence to study its effect on folding by circular dichroism and computational experiments.

\subsection{Design and synthesis of adamantane $\gamma$-amino acid}

Aiming to prepare heteropeptides incorporating the adamantane moiety, we started from Ada $\mathbf{1}$ and synthesized the non-natural $\gamma$-amino acid 3a (Scheme 1). The starting Ada $\mathbf{1}$ was obtained following the protocol previously reported by us. ${ }^{[20]}$ Two of the bridgehead positions present one free carboxylic acid and one free amino group, respectively. The two remaing bridgehead carboxyl groups were maintained protected as methyl esters. These protecting groups allow to control the peptide synthesis and avoid side-reactions during the repeated couplings in SPPS. Methyl esters can be eventually removed at the end of the synthesis to obtain a fully deprotected peptide.

To obtain the desired amino acid 3a, two synthetic routes were possible. The first consists in the selective esterification of two acid groups, but it was discarded as it lacks in selectivity. The second approach, which was eventually followed, corresponds to two steps (Scheme 1). Firstly the three carboxyl groups were esterified to the coresponding derivative 2. After purification, compound 2 underwent a hydrolysis using a slight eccess of potassium hydroxide in a 1:1 methanol/water mixture at $50^{\circ} \mathrm{C}$, providing the desired mono-hydrolyzed product $3 \mathbf{a}$ in $50 \%$ yield. This hydrolysis reaction was followed by LC-MS. The remaining $50 \%$ was composed of the fully-protected carboxylic acid derivative $(\mathbf{3 b}, 44 \%)$, the mono-protected carboxylic acid derivative (3c, 5\%), and the fully-deprotected carboxylic acid derivate (3d, <1\%). After neutralization of the mixture containing the different products 3 using $\mathrm{HCl}$ and concentration in vacuo, the unreacted compound $\mathbf{3 b}$ could be recycled by extraction using hot acetonitrile and used in a new hydrolysis process. The negligible amounts of the other two side-products (3c and 3d) were easily removed after protection of the amino group. 


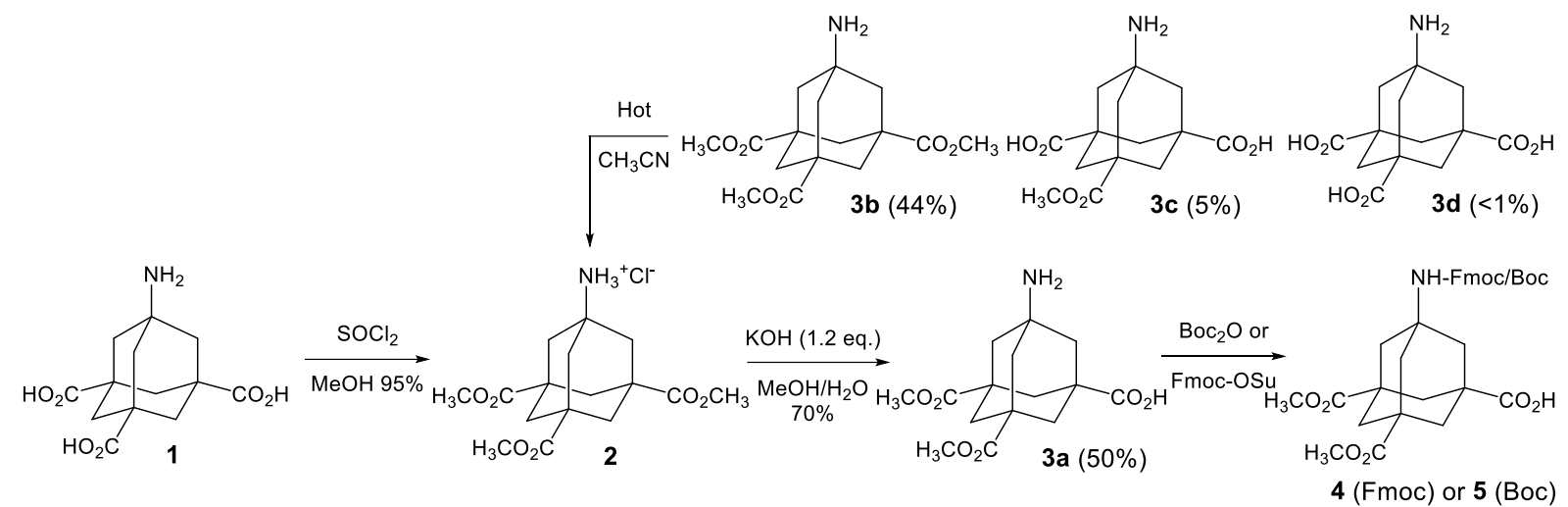

Scheme 1. Synthesis of 3-amino-5,7-bis(methoxycarbonyl)adamantane-1-carboxylic acid 3a and its $N$-protected forms $\mathbf{4}$ and $\mathbf{5}$.

To use compound compound 3a in SPPS of the different adamantane heteropeptides, the free amino group was protected. The Fmoc strategy is the most commonly used in SPPS. Different attempts to protect the amine with Fmoc were made, leading to compound 4 (Table S1). Unfortunately, the results indicated a low nucleophilicity of the amino group on adamantane. Fmoc-chloride and Fmoc- $N$-hydroxysuccinimide ester did not introduce Fmoc efficiently. Only traces of product were isolated (Table S1). Different organic and inorganic bases were also used during the couplings, where potassium carbonate gave the best but still a low yield. In addition to the low yield, the reaction was not reproducible and the yield decreased when the reaction was scale-up to hundred of milligrams. For this reason we changed our strategy, and we decided to use Boc protection. Once again, different conditions were tested leading to the formation of Boc-protected $\gamma$-amino acid 5 (Table S2). While the reaction did not occur in THF, we obtained better yields in methanol. It is interesting to note the effect of the temperature. When the temperature was rised, the yield slightly decreased. We found a good compromise in performing the reaction at $40{ }^{\circ} \mathrm{C}$ for $48 \mathrm{~h}$, where the Boc anhydride displayed a good stability. Using this condition, we isolated compound $\mathbf{5}$ in $55 \%$ yield. The optimized conditions allowed to synthesize Boc-Ada(Me $)_{2}-\mathrm{OH}$ at a scale of several hundred milligrams.

With Boc-Ada(Me) ${ }_{2}-\mathrm{OH} 5$ in hand we designed a series of side-chain protected and deprotected octapeptides to study the effect of such bulky amino acid on peptide folding (Table 1). 
Table 1. Peptide sequences containing adamantane $\gamma$-amino acid 3a.

\begin{tabular}{|c|c|}
\hline Entry & Peptide sequences \\
\hline 6 & H-L-Tyr-Gly-Ada(Me)2-Gly-Ada(Me)2-Gly-Ada(Me)2-Gly-OH \\
\hline 7 & H-D-Tyr-Gly-Ada(Me) ${ }_{2}$-Gly-Ada(Me) ${ }_{2}-\mathrm{Gly}-\mathrm{Ada}(\mathrm{Me})_{2}$-Gly-OH \\
\hline 8 & H-L-Tyr-Gly-Ada-Gly-Ada-Gly-Ada-Gly-OH \\
\hline 9 & H-D-Tyr-Gly-Ada-Gly-Ada-Gly-Ada-Gly-OH \\
\hline
\end{tabular}

All sequences start with a Gly at the $C$-terminus and include an additional Gly before the $N$ terminal tyrosine. We decided to add an initial achiral amino acid to have a short spacer before the incorporation of the first bulky adamantane $\gamma$-amino acid onto the resin and to better determine the initial loading of the resin. The peptides are constituted by a threefold repetition of the Gly-Ada sequence. We then inserted the N-terminal L- or D-tyrosine to observe if this chiral amino acid was able to induce a preferential conformation during the folding (vide infra). The presence of the tyrosine also helped during the purification steps (due to its strong absorbance in the UV region) and for the calculation of the exact concentration of the peptides in solution.

\subsection{Optimization of the SPPS protocols}

The coupling between admantane 3a and the other amino acids on solid support is likely as difficult as linking the amino acid Aib ( $\alpha$-amino isobutyric acid). ${ }^{[23]}$ Indeed, the $N$-acylation of the $\gamma$-amino acid 3a, to prepare the Boc or Fmoc protected derivative, confirmed the low nucleophilicity of the amino group on adamantane. To overcome the risk of incomplete couplings, we decided to perform SPPS under controlled microwave (MW) heating. We selected the TentaGel resin and 4-hydroxymethylbenzoic acid (HMBA) as linker. This linker allowed us to combine the Boc and Fmoc strategies during the coupling of adamantane 3a (Bocprotected) and the natural amino acids (Fmoc-protected), respectively. It was essential that $(i)$ the building block was stable duing the coupling conditions and that (ii) the conditions for repetitive removal of the Boc groups were compatible with the stability of the linker and the 
side-chain methyl esters. The stability of the Boc-protected adamantane amino acid $\mathbf{5}$ was studied in different coupling and deprotection conditions. Boc-Ada(Me) ${ }_{2}-\mathrm{COOH} 5$ must be stable in basic condition (Fmoc removal) and against strong nucleophiles (cleavage from the resin). Moreover, Boc must be removed selectively without affecting the methyl esters. Thus, different conditions were tested, using LC-MS analysis (Table S3).

After these preliminary tests, we started to incorporate Boc-Ada(Me $)_{2}-\mathrm{OH} 5$ into the short peptide sequence H-L-Tyr-Gly-Ada(Me $)_{2}-\mathrm{Gly}-\mathrm{OH}$ as the cleavage conditions from the resin needed the setup of an optimized protocol. TentaGel S-NH 2 resin was reacted with HMBA via a classical peptide bond synthesis. Then we coupled Fmoc-Gly-OH by ester formation, with a yield of $71 \%$. To save the precious Boc-Ada(Me $)_{2}-\mathrm{OH} 5$ only 1.5 eq were used in the following step (see experimental details in SI). The Kaiser test gave a negative result. ${ }^{[24]}$ The insertion of the subsequent Fmoc-Gly-OH residue was performed under MW optimized heating conditions (Table S4 and S5). The peptide sequence was completed by the addition of the final tyrosine residue, leading to an overall loading of $75 \%$. With the H-L-Tyr-Gly-Ada(Me)2-Gly-HMBATentagel in hand we focused on the conditions to remove the peptide from the solid support. The purpose was to find a way to obtain a fully deprotected peptide, hence deprotected adamantane side-chains and $\mathrm{COOH}$ at the $C$-terminus. After trying different basic conditions at room and high temperature (Table 2) without success, we were able to remove the peptide in the presence of sodium methoxide in methanol. The risk was to generate a peptide with the $C$ terminal protected as a methyl ester. Indeed, treatment with sodium methoxide gave the expected peptide with the protecting groups on the side-chains of adamantane and free $C$ terminal $\mathrm{COOH}$, together with a second peptide with the $C$-terminal part as methyl ester, at different ratios depending on the conditions used (Table 2).

Table 2. Cleavage conditions tested to remove the peptide from the resin.

\begin{tabular}{|c|c|c|c|}
\hline Solutions $^{\star}$ & Conditions & Kaiser test & Result \\
\hline $\mathrm{NaOH} \mathrm{0.25} \mathrm{M}$ & $30 \mathrm{~min}, \mathrm{rt}$ & Positive & $\mathrm{Nd}$ \\
\hline
\end{tabular}




\begin{tabular}{|c|c|c|c|}
\hline $\mathrm{NaOH} 0.5 \mathrm{M}$ & $30 \mathrm{~min}, \mathrm{rt}$ & Positive & $\mathrm{Nd}$ \\
\hline $\mathrm{NaOH} 0.5 \mathrm{M}$ in $\mathrm{MeOH}$ & $30 \mathrm{~min}, \mathrm{rt}$ & Positive & $\mathrm{Nd}$ \\
\hline LiOH $0.5 \mathrm{M}$ in THF & $30 \mathrm{~min}, \mathrm{rt}$ & Positive & $\mathrm{Nd}$ \\
\hline $\mathrm{LiOH} 1 \mathrm{M}$ in $\mathrm{MeOH}$ & $1 \mathrm{~h}, 50^{\circ} \mathrm{C}$ & Positive & $\mathrm{Nd}$ \\
\hline NaOMe $0.25 \mathrm{M}$ & $30 \mathrm{~min}, \mathrm{rt}$ & Negative & \multirow{2}{*}{$\begin{array}{c}2 \text { Peaks in HPLC, } 50(-\mathrm{COOH}) / 50 \\
(-\mathrm{COOMe}) \text { at the } C \text {-terminus and } \\
\text { Ada side-chains protected }\end{array}$} \\
\hline NaOMe $0.5 \mathrm{M}$ & $30 \mathrm{~min}, \mathrm{rt}$ & Negative & \\
\hline $\begin{array}{c}\text { NaOMe } 0.5 \mathrm{M} \\
\text { freshly prepared }\end{array}$ & $30 \mathrm{~min}, \mathrm{rt}$ & Negative & $\begin{array}{c}2 \text { Peaks in HPLC } \\
75(-\mathrm{COOH}) / 25(-\mathrm{COOMe})\end{array}$ \\
\hline
\end{tabular}

* Note: $t$-Bu and Fmoc protecting groups on tyrosine and $N$-terminus, respectively, were removed before the cleavage test. Nd: not detected.

As it was impossible to minimize the percentage of $C$-terminal peptide methyl ester, we decided to use sodium methoxide to remove the subsequent long peptides, and separate the two compounds by HPLC. This allowed to obtain a peptide with the protected side-chains and free C-terminal $\mathrm{COOH}$ and a second fully peptide that underwent a hydrolysis of all methyl esters with $\mathrm{NaOH}$ to prepare a fully deprotected peptide.

\subsection{Synthesis of the long adamantane heteropeptides}

After assessing the optimized procedures described above, we proceeded with the synthesis of the different peptide sequences reported in Table 1 (see SI for details). Adamantane containing peptides 6-9 were successfully prepared, purified and characterized by HPLC and mass spectrometry. Figure S1 shows the mass spectra of the L-peptides with and without protecting groups on the side-chains of adamantane.

\subsection{Folding study}

Circular dichroism (CD) spectroscopy was used to study whether the peptides 6-9 were able to adopt a secondary structure. The concentration of each peptide, following its weight and solubilization in the appropriate solvent, was first determined by UV titration using the optical absorption of the tyrosine (Figure S2). 
The folding of the peptides was studied initially in methanol. Protected peptides 6 and 7 displayed an interesting signal in the CD in the range $200-240 \mathrm{~nm}$ (centered at $230 \mathrm{~nm}$ ). These signals likely account for a stable conformation adopted by the peptides. As expected, the signals are symmetric when we compare L- or D-tyrosine containing peptides (Figure 1), confirming that this chiral amino acid is able to induce a specular folded structure.

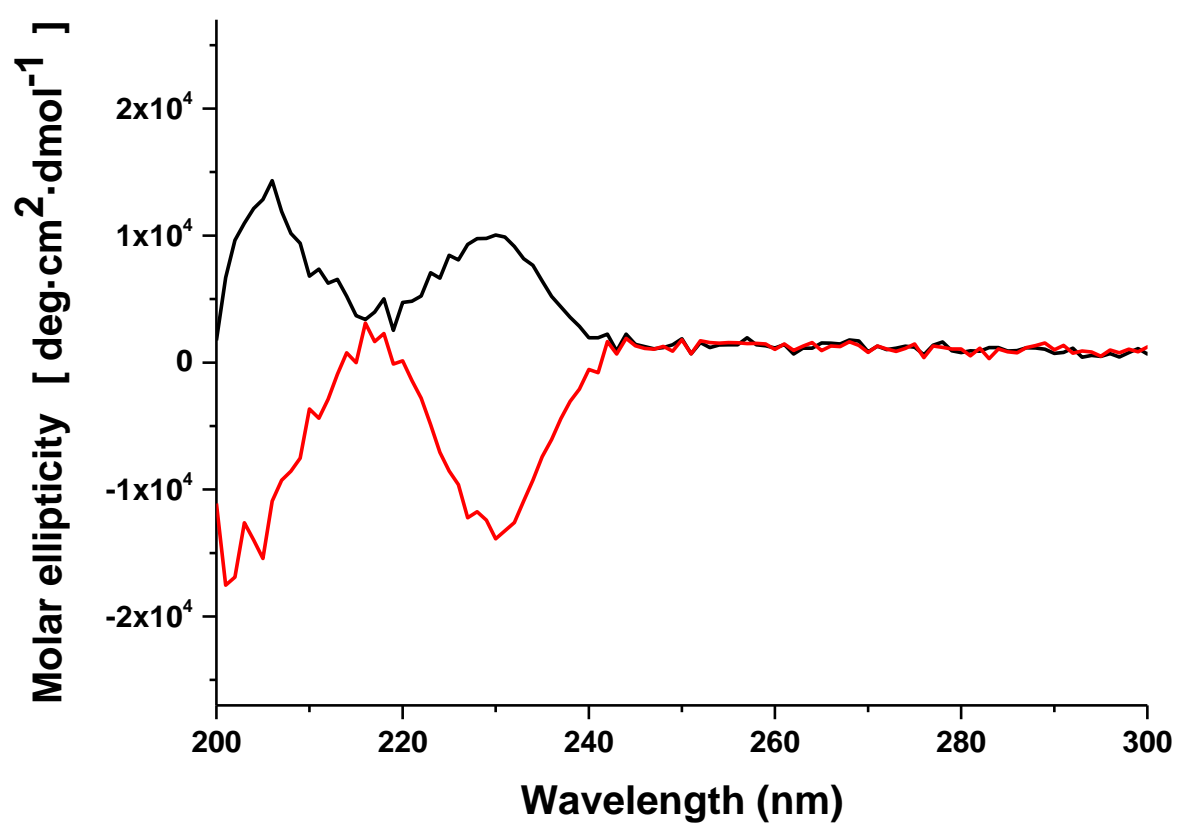

Figure 1. CD spectra of H-L-Tyr-Gly-Ada(Me) ${ }_{2}-\mathrm{Gly}-\mathrm{Ada}(\mathrm{Me})_{2}-\mathrm{Gly}-\mathrm{Ada}(\mathrm{Me})_{2}-\mathrm{Gly}-\mathrm{OH} 6$ (black curve) H-D-Tyr-Gly-Ada(Me) ${ }_{2}-\mathrm{Gly}-\mathrm{Ada}(\mathrm{Me})_{2}-\mathrm{Gly}-\mathrm{Ada}(\mathrm{Me})_{2}-\mathrm{Gly}-\mathrm{OH} 7$ (red curve) in $\mathrm{MeOH}$.

The obtained signals do not correspond to an $\alpha$-helix or a $\beta$-sheet signature, but they are rather indicative of a conformation stabilized by intramolecular hydrogen bonding (vide infra). The same analysis was performed on the unprotected peptide $\mathbf{8}$ and $\mathbf{9}$. These peptides do not adopt a folded conformation in methanol (Figure S3). Finally, we measured the ellipticity of the peptides in 2,2,2-trifluoroethanol (TFE), which is often used to induce peptide folding of $\alpha$ helicity. ${ }^{[25]}$ Once again, a clear and specular signal was observed around $225 \mathrm{~nm}$ for the 
protected peptides 6 and 7 (Figure 2). The unprotected peptides were not able to fold in TFE, due to poor solubility.

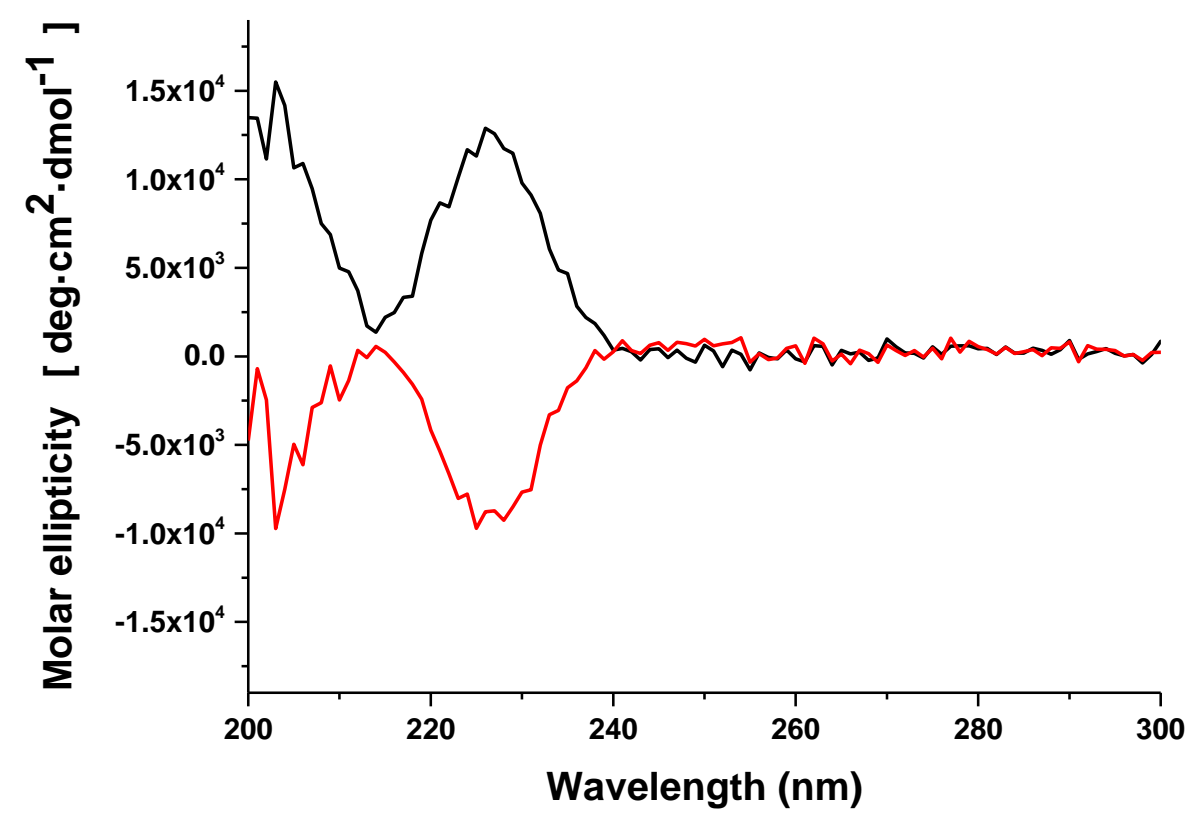

Figure 2. CD spectra of H-L-Tyr-Gly-Ada(Me $)_{2}-\mathrm{Gly}-\mathrm{Ada}(\mathrm{Me})_{2}-\mathrm{Gly}-\mathrm{Ada}(\mathrm{Me})_{2}-\mathrm{Gly}-\mathrm{OH} 6$ (black curve) H-D-Tyr-Gly-Ada(Me) ${ }_{2}-\mathrm{Gly}-\mathrm{Ada}(\mathrm{Me})_{2}-\mathrm{Gly}-\mathrm{Ada}(\mathrm{Me})_{2}-\mathrm{Gly}-\mathrm{OH} 7$ (red curve) in TFE.

\subsection{Molecular dynamics simulations}

Although sharing some characteristics with previous systems (e.g. restrained $\alpha / \gamma$-peptides), ${ }^{[17]}$ the Ada residues in the heteropeptides herein differ by having a rigid $\mathrm{C}_{\alpha}-\mathrm{C}_{\beta}-\mathrm{C}_{\gamma}$ backbone and by being substantially bulkier. Given these departures from previous $\alpha / \gamma$-peptide designs, we expected at the outset that the Ada-heteropeptides might populate new types of conformations In order to further examine the type and the behaviour of the conformations adopted by the heteropeptides 6 and 7 we used molecular dynamics (MD) simulations.We carried out MD simulations on peptides $\mathbf{6}$ and $\mathbf{7}$ in TFE in order to determine their solution structures and to understand how the chirality inversion of the single N-terminal Tyr could induce overall chirality in each peptide. 
Overall, both peptides behaved dynamically similar in MD simulations as expected for stereoisomers, and the average properties (e.g for radius of gyration, $\mathrm{R}_{\mathrm{gyr}}$, see below) were identical within the sampling precision of MD. The peptides were rather flexible and dynamically populated different conformations. As seen from the radius of gyration $\left(\mathrm{R}_{\mathrm{gyr}}\right)$ calculated for the MD trajectories (Figure S4 and S5) compact conformations ( $\mathrm{R}_{\mathrm{gyr}}<8 \AA$ ) were generally favored, while extended conformations ( $\mathrm{R}_{\mathrm{gyr}} 8.5-11 \AA$ ) were rare and short-lived. Cyclic conformations comprised most of the compact conformations and persisted for ca. $50 \%$ of each MD trajectory. The cyclic conformations were stabilized by at least one hydrogen bond (salt bridge) between the Gly8 C-terminal carboxylate and the protonated N-terminal amine of L-Tyr1 or D-Tyr1 for peptide 6 and 7, respectively. Similar zwitterion driven formation of circular conformations in solution have previously been reported. ${ }^{[26]}$ A subset of the cyclic conformations ( $16 \%$ of each MD trajectory) were further stabilized by a hydrogen bond between the Tyr1 phenolic $\mathrm{OH}$ and the Gly4 backbone amide oxygen. The comparison of this subset of conformations across the two simulations showed that the most populated conformation for $\mathbf{6}$ and $\mathbf{7}$ were mirror images of each other. These conformations are shown as insets in Figure $3 \mathrm{a}$ and $3 \mathrm{~b}$, respectively. To quantify the chirality of these conformations, we defined a dihedral angle for the atoms labeled 1 to 4 . With this definition, the dihedral angle had the same absolute value ( 25 degrees) but opposite sign for the two mirror conformations. The histograms for the dihedral angle are shown as blue bars in Figure $3 \mathrm{a}$ and $3 \mathrm{~b}$, and demonstrate the preference for opposite peptide chiralities in the two simulations.

Overall, MD simulations showed that peptides 6 and 7 preferentially populated compact conformations, of which a subset ( $\sim 16 \%$ of the MD trajectory for each peptide) assumed welldefined cyclic geometries stabilized by two hydrogen bonds involving Tyr1. Through these interactions, the chirality of Tyr1 induced overall chirality in the cyclic conformations, thus giving mainly structures of the form shown inset in Figures $3 a$ and $3 b$ for peptides 6 and 7, respectively. We propose that these mirror-image structures and their closely associated 
conformers (the largest mode of each histogram in Figure 3a and 3b) are the principal solution species giving rise to the opposite CD signals measured for peptide $\mathbf{6}$ and $\mathbf{7}$.
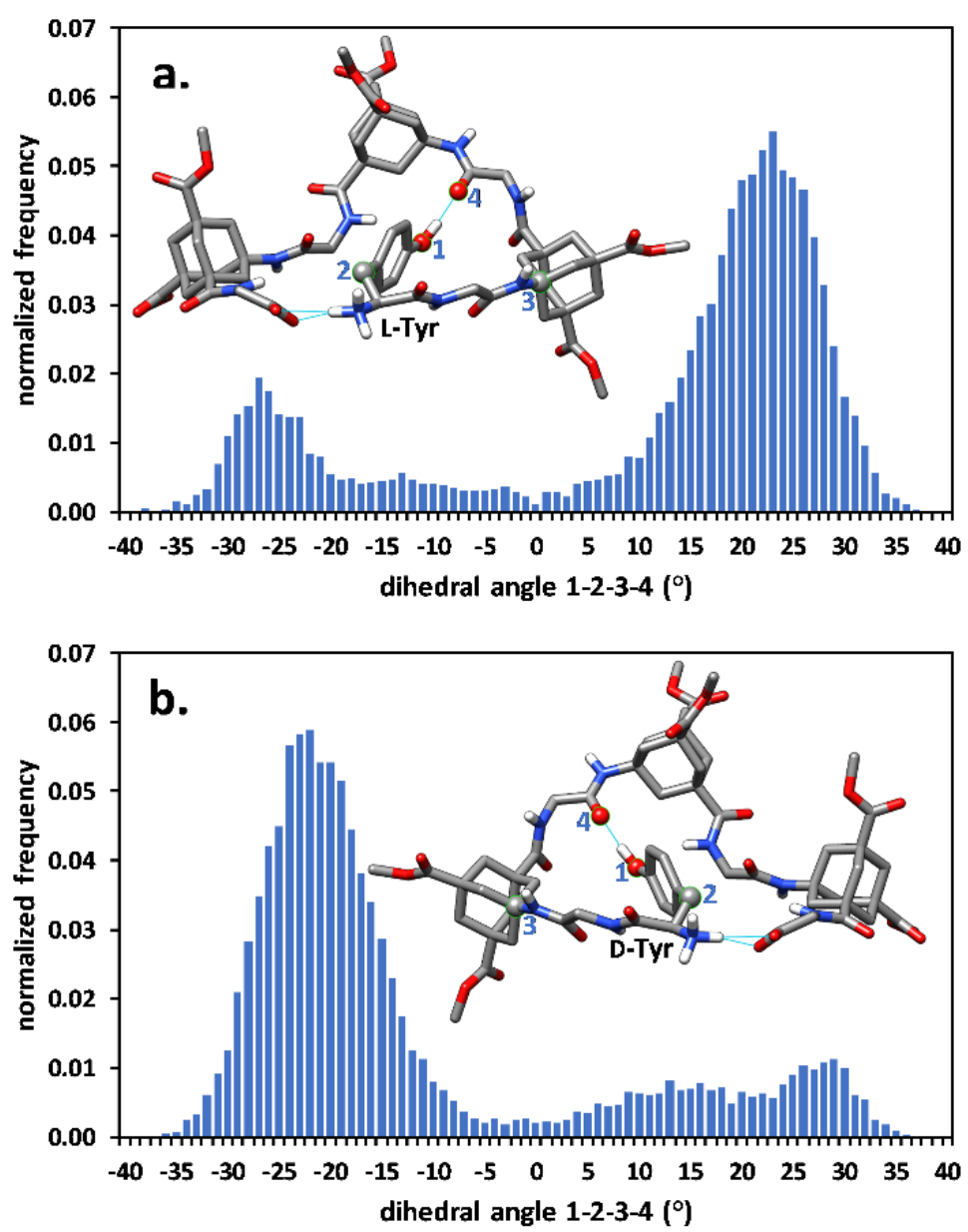

Figure 3. Mirror-image structures of hydrogen-bond stabilized cyclic conformations comprising ca. $16 \%$ of the MD simulation trajectories for (a) peptide 6 and (b) peptide 7. Nonpolar hydrogens are not shown. A dihedral angle defined by atoms labeled $1-4$ was used as a proxy for overall peptide chirality. Histograms for this dihedral measured for the $16 \%$ cyclic subset of each trajectory are shown as blue bars, demonstrating the chiral preference for each simulation. The displayed structures represent the largest mode in each histrogram and are the suggested principal structures giving rise to the measured CD spectra.

We note that the salt-bridge between the oppositely charged termini appears to be a key driver of the cyclic conformations shown in Figure 3 since a simulation on peptide 7 in its anionic 
form (see Figure S6 and S7) yields a much lower population of such conformations. This may be leveraged in future designs when a $\mathrm{pH}$ mediated control of cyclic conformations is desired.

\section{Conclusion}

In summary, we have developed the synthesis of a partially protected adamantane $\gamma$-amino acid starting from 1-bromoadamantane for solid-phase peptide synthesis. A robust protocol to incorporate adamantane derivatives in a growing peptide on a solid support assisted by microwave heating was developed, using the minimum amount of protected amino acid. This involved a Fmoc and Boc mixed strategy with selective deprotection conditions of each temporary protecting group that did not affect the linker or the adamantane side-chain methyl groups. The desired heteropeptides were then prepared and studied using circular dichroism in methanol and trifluoroethanol, revealing CD signals of opposite sign for peptides with a single N-terminal D-Tyr or L-Tyr, respectively. MD simulations showed that the heteropeptides could form cyclic conformations with different overall chirality depending on the chirality of the $\mathrm{N}$ terminal Tyr, providing a plausible structural interpretation of the CD results.

This work combined the design and synthesis of novel adamantane building blocks, with the ability to use precise microwave heating to assemble sterically hindered monomers into well defined and recurring cyclic conformations.

\section{Experimental Section}

\section{Trimethyl aminoadamantane-1,3,5-tricarboxylate (6)}

The synthesis of 1,3,5-carboxy-7-amine adamantane $\mathbf{1}$ and trimethyl aminoadamantane-1,3,5tricarboxylate 2 from the commercially 1-bromoadamatane is described in Ref. [20].

\section{3-amino-5,7-bis(methoxycarbonyl)adamantane-1-carboxylic acid (3)}

A potassium hydroxide $(327 \mathrm{mg}, 5.8 \mathrm{mmol})$ solution in water $(50 \mathrm{~mL})$ was added to a solution of trimethyl aminoadamantane-1,3,5-tricarboxylate $2(1.20 \mathrm{~g}, 3.8 \mathrm{mmol})$ in methanol $(50 \mathrm{~mL})$ 
and the mixture was stirred at $60{ }^{\circ} \mathrm{C}$ for at least $3 \mathrm{~h}$. LC-MS and TLC analysis allowed to follow the hydrolysis of the methyl esters. $\mathrm{pH}$ was adjusted to 7 using $\mathrm{HCl} 6 \mathrm{~N}(1.0 \mathrm{~mL})$ and the solvent was removed under vacuum. The crude product was washed with hot acetonitrile (to remove the starting material 3b) and dried under vacuum to give the desired amino acid 3a as a white powder (560 mg, $1.9 \mathrm{mmol}, 50 \%)$. The bis-deprotected and fully-deprotected derivatives represent less than $5 \%$ of the compound (as found by LC-MS), and they are totally removed by column chromatography after $N$-acylation. ${ }^{1} \mathrm{H}$ NMR (MeOD, $\left.500 \mathrm{MHz}\right) \delta: 3.71\left(\mathrm{~s}, 6 \mathrm{H}, \mathrm{CH}_{3}\right)$, 2.08-1.92 (m,12H, $\left.\mathrm{CH}_{2}\right) .{ }^{13} \mathrm{C} \mathrm{NMR}\left(\mathrm{CDCl}_{3}, 75 \mathrm{MHz}\right) \delta: 176.02,174.56,52.35,51.52,48.46$, 42.77, 39.74, 39.60, 38.01, 37.86. FT-IR (neat, $v / \mathrm{cm}^{-1}$ ): $3306(b r), 1725,1548$. MS (ESI) $m / z$ : 434.18 $[\mathrm{M}+\mathrm{Na}]^{+}$. MS (ESI) $m / z: 312.32[\mathrm{M}+\mathrm{H}]^{+}$.

\section{3- $N$-Fmoc-5,7-bis(methoxycarbonyl)adamantane-1-carboxylic acid (4)}

3-Amino-5,7-bis(methoxycarbonyl)adamantane-1-carboxylic acid 3a (42 mg, $0.136 \mathrm{mmol}$ ) and potassium carbonate $(56.5 \mathrm{mg}, 0.41 \mathrm{mmol})$ were solubilized in water $(3 \mathrm{~mL})$ and cooled at $0{ }^{\circ} \mathrm{C}$. Dioxane $(1 \mathrm{~mL})$ was added (partial precipitation was observed). Fmoc-chloride (106 mg, 0.41 $\mathrm{mmol})$ in dioxane $(1.5 \mathrm{~mL})$ was added dropwise with vigorous stirring. After $6 \mathrm{~h}$ at $\mathrm{rt}$, the dioxane was removed under vacuum. The aqueous phase was acidified with $\mathrm{HCl} 6 \mathrm{~N}$ to reach $\mathrm{pH} 2-3$ and the compound was extracted using AcOEt $(4 \times 20 \mathrm{~mL})$. The combined organic phases were dried on magnesium sulfate, filtered and concentrated to give $\mathbf{4}$ as a white powder (32 mg,

$0.061 \mathrm{mmol}, 30 \%) .{ }^{1} \mathrm{H} \mathrm{NMR}\left(\mathrm{CDCl}_{3}, 500 \mathrm{MHz}\right) \delta: 7.73(m, 2 \mathrm{H}, \mathrm{Ar}-H), 7.54(m, 2 \mathrm{H}, \mathrm{Ar}-H)$, $7.36(m, 2 \mathrm{H}, \mathrm{Ar}-H), 7.29(m, 2 \mathrm{H}, \mathrm{Ar}-H), 4.78\left(\right.$ br s $\left., 1 \mathrm{H}, \mathrm{CH} H_{2}\right), 4.35\left(s, 1 \mathrm{H}, \mathrm{CH} H_{2}\right), 4.17(t, 1 \mathrm{H}$, $\mathrm{CH}), 3.66(\mathrm{~s}, 6 \mathrm{H}, \mathrm{CH}), 2.09-1.76\left(\mathrm{~m}, 10 \mathrm{H}, \mathrm{CH}_{2}\right), 1.36\left(\right.$ br s, $\left.2 \mathrm{H}, \mathrm{CH}_{2}\right) .{ }^{13} \mathrm{C} \mathrm{NMR}\left(\mathrm{CDCl}_{3}, 125\right.$ MHz) $\delta: 180.25,180.04,175.21,160.26,159.93,154.36,143.81,141.32,127.74,127.13$, $124.97,123.94,120.07,115.79,113.51,66.25,52.22,51.67,47,19,42.91,42.76,41.17,40.96$, 38.47, 38.26. FT-IR (neat, $v / \mathrm{cm}^{-1}$ ): 3361, 1736, 1714, 1692, 1523. MS (ESI) $\mathrm{m} / z: 556.20$ $[\mathrm{M}+\mathrm{Na}]^{+}$.

\section{3-N-Boc-5,7-bis(methoxycarbonyl)adamantane-1-carboxylic acid (5)}


3-Amino-5,7-bis(methoxycarbonyl)adamantane-1-carboxylic acid 3a (60 mg, $0.19 \mathrm{mmol}$ ) was solubilized in $\mathrm{MeOH}(25 \mathrm{~mL}) . \mathrm{NEt}_{3}(134 \mu \mathrm{L}, 0.96 \mathrm{mmol})$ and $\mathrm{Boc}_{2} \mathrm{O}(126 \mathrm{mg}, 0.58 \mathrm{mmol})$ were added. Mixture was stirred at $50{ }^{\circ} \mathrm{C}$. After $24 \mathrm{~h}$, a second addition of $\mathrm{Boc}_{2} \mathrm{O}(30 \mathrm{mg}, 0.13$ mmol $)$ and $\mathrm{NEt}_{3}(30 \mu \mathrm{L}, 0.21 \mathrm{mmol})$ was done and the mixture was stirred for another $24 \mathrm{~h}$ at $50{ }^{\circ} \mathrm{C}$. Then, methanol was removed under vacuum and acidic water was added. The compound was extracted with AcOEt $(3 \times 25 \mathrm{~mL})$. The combined organic phases were dried on $\mathrm{MgSO}_{4}$, filtered, and concentrated. The compound was purified by column chromatography on silica gel (eluant: AcOEt/cyclohexane (3/7)) to give 5 as a white powder (38 mg, $0.09 \mathrm{mmol}, 55 \%$ ). ${ }^{1} \mathrm{H} \mathrm{NMR}\left(\mathrm{CDCl}_{3}, 500 \mathrm{MHz}\right) \delta: 4.55(s, 1 \mathrm{H}, \mathrm{NH}), 3.69\left(s, 6 \mathrm{H}, \mathrm{CH}_{3}\right), 2.04-1.90\left(m, 12 \mathrm{H}, \mathrm{CH}_{2}\right)$, $1.40\left(s, 9 \mathrm{H}, \mathrm{CH}_{3}\right) .{ }^{13} \mathrm{C} \mathrm{NMR}\left(\mathrm{CDCl}_{3}, 125 \mathrm{MHz}\right) \delta: 180.49,175.35,153.89,79.44,51.19,51.34$, 42.92, 42.76, 41.32, 41.12, 38.54, 38.32, 28.24. FT-IR (neat, $v / \mathrm{cm}^{-1}$ ): 3202, 1722, 1698, 1511. MS (ESI) $m / z: 434.18[\mathrm{M}+\mathrm{Na}]^{+}$.

\section{Molecular Dynamics Simulations}

MD simulations were carried out in Desmond ${ }^{[27]}$ for $4 \mu$ s in a cubic 2,2,2-trifluoroethanol solvent box (15 Å buffer) with the OPLS3 force field. ${ }^{[28]}$ Default settings were used for the NPT ensemble with a temperature of $300 \mathrm{~K}$ and a pressure of 1 bar. The system had zero net charge and no counterions were added. The first $250 \mathrm{~ns}$ of the $4 \mu$ s simulations were considered to be part of the equilibration, and were excluded from analysis. The MD trajectories were analyzed and visualized with $\mathrm{VMD}^{[29]}$ and Chimera. ${ }^{[30]}$ Adequate sampling of the conformational space during $3750 \mathrm{~ns}$ was indicated for each simulation by the similar distributions of the radius of gyration for the two simulations (Figures S4 and S5).

\section{Monitoring hydrogen bonds and salt bridges}

Hydrogen bonds between $\mathrm{H}, \mathrm{N}$, and $\mathrm{O}$ atoms were detected with VMD, using geometric criteria with slightly relaxed cutoff values compared to the VMD defaults. Thus an interaction between 
$\mathrm{H}, \mathrm{N}, \mathrm{O}$ atoms counted as a hydrogen bond if the donor-hydrogen-acceptor angle deviated at most 30 degrees from linear and if the donor-acceptor distance was below or equal to $3.5 \AA$. For salt bridges, specifically the interaction between the C-terminal carboxylate anion and the protonated N-terminal amine, we employed the definition in the VMD salt bridge plugin ${ }^{[29]}$ i.e. "A salt bridge can be defined as an interaction between two groups of opposite charge in which at least one pair of heavy atoms is within hydrogen bonding distance.“. With the criteria used in this work, the salt-bridge between the C- and N-terminals was found to persist for $54 \%$ (LTyr) and 59\% (D-Tyr) of the simulation time.

\section{Acknowledgements}

The authors gratefully acknowledge the financial support from the Agence Nationale de la Recherche (ANR) through the LabEx project Chemistry of Complex Systems (ANR-10LABX-0026_CSC). This work was partly supported by the Centre National de la Recherche Scientifique (CNRS), and the International Center for Frontier Research in Chemistry (icFRC). A. A. and A. B. wish to thank the CNRS PICS echange programm 2015. The VILLUM FONDEN is thanked for funding Biomolecular Nanoscale Engineering Center (BioNEC), a VILLUM center of excellence, grant number VKR022710. The authors wishes to thank S. Guo, R. Soltani and C. Martín for the characterization and preparation of the figures. 


\section{References}

[1] S. H. Gellman, Acc. Chem. Res. 1998, 31, 173-180.

[2] B. A. F. Le Baillya, J. Clayden, Chem. Commun. 2016, 52, 4852-4863.

[3] D. J. Hill, M. J. Mio, R. B. Prince, T. S. Hughes, S. J. Moore, Chem. Rev. 2001, 101, $3893-4012$

[4] N. Eccles, B. A. F. Le Bailly, F. Della Sala, I. J. Vitórica-Yrezábal, J. Clayden, S. J.

Webb, Chem. Commun. 2019, 55, 9331-9334.

[5] C. Tomasini, I. Huc, D. J. Aitken, F. Fülöp, Eur. J. Org. Chem. 2013, 17, 3408-3409.

[6] T. A. Martinek, F. Fülöp, Chem. Soc. Rev. 2012, 41, 687-702.

[7] D. Seebach, A. K. Beck, D. J. Bierbaum, Chem. Biodivers. 2004, 1, 1111-1239.

[8] S. H. Choi, I. A. Guzei, L. C. Spencer, S. H. Gellman, J. Am. Chem. Soc. 2008, 130, 65446550.

[9] I. M. Mándity, L. Fülöp, E. Vass, G. K. Tóth, T. A. Martinek, F. Fülöp Org. Lett. 2010, 12, $5584-5587$

[10] Y. Patil-Sen, S. R. Dennison, T. J. Snape, Bioorg. Med. Chem. 2016, 24, 4241-4245.

[11] M. A. Gelman, S. Richter, H. Cao, N. Umezawa, S. H. Gellman, T. M. Rana, Org. Lett. 2003, 5, 3563-3565.

[12] A. D. Bautista, J. S. Appelbaum, C. J. Craig, J. Michel, A. Schepartz, J. Am. Chem. Soc. 2010, 132, 2904-2906.

[13] M. Kaszowska, A. S. Norgren, P. I. Arvidson, C. Sandström, Carbohydr. Res. 2009, 344, 2577-2580.

[14] C. Baldauf, R. Günther, H.-J. Hofmann, J. Org. Chem. 2006, 71, 1200-1208.

[15] L. Guo, Y. Chi, A. M. Almeida, I. A. Guzei, B. K. Parker, S. H. Gellman, J. Am. Chem. Soc. 2009, 131, 16018-16020.

[16] B. F. Fisher, L. Guo, B. S. Dolinar, I. A. Guzei, S. H. Gellman, J. Am. Chem. Soc. 2015, 137, 6484-6487. 
[17] B. F. Fisher, S. H. Gellman, J. Am. Chem. Soc. 2016, 138, 10766-10769.

[18] A. Štimac, M. Šekutor, K. Mlinarić-Majerski, L. Frkanec, R. Frkanec, Molecules 2017, 22, pii: E297.

[19] M. Grillaud, A. Bianco, J. Pept. Sci. 2015, 21, 330-345.

[20] G. Lamanna, J. Russier, C. Ménard-Moyon, A. Bianco, Chem. Commun. 2011, 47, 89558957.

[21] G. Lamanna, J. Russier, H. Dumortier, A. Bianco, Biomaterials 2012, 33, 5610-5617.

[22] G. Lamanna, M. Grillaud, C. Macri, O. Chaloin, S. Muller, A. Bianco, Biomaterials 2014, 35, 7553-7561.

[23] S. R. Haynes, S. D. Hagins, M. M. Juban, P. H. Elzer, R. P. Hammer, J. Pept. Res. 2005, $66,333-347$.

[24] E. Kaiser, R. L. Colescott, C. D. Bossinger, P. I. Cook, Anal. Biochem. 1970, 34, 595598.

[25] M. Vincenzi, F. A. Mercurio, M. Leone, Curr. Protein Pept. Sci. 2019, 20, 425-451.

[26] A. K. Yudin, Chem. Sci. 2015,6, 30-49

[27] K. J. Bowers, D. E. Chow, H. Xu, R. O. Dror, M. P. Eastwood, B. A. Gregersen, J. L.

Klepeis, I. Kolossvary, M. A. Moraes, F. D. Sacerdoti, J. K. Salmon, Y. Shan and D. E. Shaw, Proceedings of the ACM/IEEE Conference on Supercomputing (SC06) 2006, ACM, New York, USA.

[28] E. Harder, W. Damm, J. Maple, C. Wu, M. Reboul, J. Y. Xiang, L. Wang, D. Lupyan, M. K. Dahlgren, J. L. Knight, J. W. Kaus, D. S. Cerutti, G. Krilov, W. L. Jorgensen, R. Abel and R. A. Friesner, J. Chem. Theor. Comput. 2016, 12, 281-296.

[29] W. Humphrey, A. Dalke and K. Schulten, J. Mol. Gra. 1996, 14, 33-38.

[30] E. F. Pettersen, T. D. Goddard, C. C. Huang, G. S. Couch, D. M. Greenblatt, E. C. Meng and T. E. Ferrin, J. Comput. Chem. 2004, 25, 1605-1612. 